\title{
Resveratrol reduces the progression of titanium particle-induced osteolysis via the Wnt/ $\beta$-catenin signaling pathway in vivo and in vitro
}

\author{
XI CHEN ${ }^{1}$, SHOUXUAN SUN ${ }^{1}$, TIANXIANG GENG ${ }^{1}$, XIN FAN ${ }^{1}$, \\ SHIFENG ZHANG ${ }^{1}$, SIJIA ZHAO ${ }^{2}$, YI GENG $^{2}$ and QUNHUA JIN $^{1}$ \\ ${ }^{1}$ Department of Orthopedic Surgery, General Hospital of Ningxia Medical University, Yinchuan, \\ Ningxia Hui Autonomous Region 750004; ${ }^{2}$ Institute of Dermatology, Chinese Academy of Medical Sciences and \\ Peking Union Medical College, Nanjing, Jiangsu 210042, P.R. China
}

Received December 2, 2019; Accepted April 26, 2021

DOI: 10.3892/etm.2021.10553

\begin{abstract}
As an activator of sirtuin 1, resveratrol has become an extensively reviewed anti-inflammatory and anti-aging drug in recent years, and it has been widely studied for the treatment of energy control and endocrine diseases. The present study attempted to characterize the role of resveratrol in osteolysis induced by titanium (Ti) alloy particles and $\mathrm{Ti}$ pins in vitro and in vivo. In vitro, bone marrow mesenchymal stem cells were cultured with Ti alloy particles to simulate osteolysis. Cell viability and the expression levels of proteins associated with osteogenesis and the Wnt/ $\beta$-catenin signaling pathway, including Runt-related transcription factor 2 (Runx2), alkaline phosphatase, osteocalcin, $\beta$-catenin, lymphoid enhancer-binding factor 1 and transcription factor 4 , were increased following treatment with resveratrol after 21 days of osteogenic differentiation. In vivo, a Ti pin model in C57BL/6J mice was used to study the anti-osteolysis effect of resveratrol on the peri-prosthetic bone. The pulling force of the Ti alloy pin was increased in a dose-dependent manner in the resveratrol groups compared with the control group. Furthermore, the results of micro-CT scanning revealed that the bone volume and the bone surface/volume ratio in the
\end{abstract}

Correspondence to: Dr Qunhua Jin, Department of Orthopedic Surgery, General Hospital of Ningxia Medical University, 692 Shengli Street, Yinchuan, Ningxia Hui Autonomous Region 750004, P.R. China

E-mail: jinqunhuanx@163.com

Abbreviations: ALP, alkaline phosphatase; BMSCs, bone marrow mesenchymal stem cells; Runx2, Runt-related transcription factor 2; Lef-1, lymphoid enhancer-binding factor 1; OCN, osteocalcin; PPAR $\gamma$, peroxisome proliferator-activated receptor $\gamma$; Res, resveratrol; Tcf-4, transcription factor 4; Ti, titanium; $\mu \mathrm{CT}$, micro-CT

Key words: resveratrol, osteogenic differentiation, Wnt/及-catenin signaling pathway, titanium alloy-particles periprosthetic tissue were increased in the resveratrol-treated groups, particularly in the high-dose resveratrol group. In addition, immunohistochemistry demonstrated that Runx2 expression was upregulated in the high-dose resveratrol group. In conclusion, the results of the present study indicated that resveratrol may inhibit Ti particle-induced osteolysis via activation of the Wnt/ $\beta$-catenin signaling pathway in vitro and in vivo.

\section{Introduction}

Wear particles, particularly titanium (Ti) alloy particles, are a major cause of the occurrence of aseptic loosening of joint prostheses, which eventually results in high healthcare costs and complex revision procedures (1). Following joint replacement, inflammation around the surface of the prosthesis induced by $\mathrm{Ti}$ alloy particles leads to bone resorption and aseptic loosening of the implants $(2,3)$. At present, various measures are taken for the prevention and treatment of aseptic loosening of joint prostheses. In addition, the use of Ti alloy particles has been markedly reduced with the development of biomaterials and prosthetic design. However, the issue of aseptic loosening remains unresolved and $\mathrm{Ti}$ alloy particles remain the main cause of aseptic loosening (4).

In recent years, strong evidence has emerged indicating that the viability of osteoblasts decreases in the presence of Ti alloy particles $\left(\sim 4.5 \times 10^{7} / \mathrm{ml}\right)$, with ensuing inhibition of osteogenic differentiation (5). Therefore, identifying a novel effective treatment strategy for promoting osteogenesis and inhibiting osteolysis in the presence of Ti alloy particles appears to be a promising approach to preventing the occurrence of aseptic loosening $(6,7)$.

As multipotent stem cells, bone marrow mesenchymal stem cells (BMSCs) can differentiate into various cell lineages, such as osteocytes, chondrocytes, adipocytes, neurocytes and muscular cells, via the activation of specific factors (8). Relatively recent studies have reported that BMSCs serve a crucial role during the occurrence of osteoporosis and aseptic loosening. Various anti-osteoporosis drugs, such as alendronate and strontium ranelate, have been demonstrated 
to effectively enhance osteogenesis and inhibit osteolysis in postmenopausal women via the Wnt/ $\beta$-catenin signaling pathway $(9,10)$. However, reliable and effective drugs that promote osteogenic differentiation of BMSCs and increase bone formation and metabolism in the presence of $\mathrm{Ti}$ alloy particles have yet to be developed.

As an activator of sirtuin (Sirt)1, resveratrol is an extensively reviewed anti-inflammatory and anti-aging drug, which has been widely investigated for the regulation of energy expenditure and treatment of endocrine diseases $(11,12)$. In addition, resveratrol is an important regulator of metabolism, it regulates gene coordination sites, telomeres and ribose, and silences related signals to enhance cell viability and longevity (13). In addition, accumulating evidence has indicated that resveratrol also has bone-protective properties. Shakibaei et al (14) reported that resveratrol promotes osteogenic differentiation of MSCs via Sirt1/Runt-related transcription factor 2 (Runx2) activation. Furthermore, resveratrol may promote osteogenic differentiation and reduce adipogenic differentiation in BMSCs via upregulation of Sirt1 and inhibition of peroxisome proliferator-activated receptor $\gamma(15)$. Therefore, resveratrol may represent a novel therapeutic approach to promoting osteogenesis in the presence of Ti alloy particles and preventing aseptic loosening. In addition, several studies have demonstrated that the Wnt/ $\beta$-catenin signaling pathway is a key regulator of several cellular activities, including differentiation, proliferation, migration and polarity (16). However, little is known regarding the association between resveratrol and the $\mathrm{Wnt} / \beta$-catenin signaling pathway in the context of aseptic loosening of joint prostheses.

In BMSCs, the Wnt/ $\beta$-catenin signaling pathway directly regulates osteogenic differentiation $(17,18)$. Jing et al (19) reported that the $\mathrm{Wnt} / \beta$-catenin signaling pathway and osteogenic differentiation are inhibited in osteoporosis. Following upregulation of the canonical Wnt/ $\beta$-catenin signaling pathway, the levels of $\beta$-catenin are increased and $\beta$-catenin is translocated into the nucleus, where it binds to $\mathrm{T}$ cell factor/lymphoid enhancer-binding factor 1 (Lef-1) and regulates downstream target gene expression (20). Furthermore, Runx2, also known as core-binding factor 1, is a key member of the Runx family of transcription factors, and serves an important role in the regulation of cell proliferation (21). Several studies have reported that Runx 2 is an essential master gene in the process of osteogenic differentiation and the expression of certain $\beta$-catenin targets $(22,23)$. An interaction between $\mathrm{Ti}$ alloy particles and periprosthetic tissues has also been reported (24).

The aim of the present study was to investigate whether treatment with resveratrol can inhibit osteolysis induced by $\mathrm{Ti}$ alloy particles in BMSCs. Additionally, an experimental mouse model of aseptic loosening was used to simulate artificial joint replacement, in order to investigate the interaction between Ti alloy particles and periprosthetic tissues, and examine the potential biochemical mechanisms underlying the action of resveratrol.

\section{Materials and methods}

BMSC culture and osteogenic differentiation. BMSCs from C57BL/6J mice and osteogenic differentiation medium were purchased from Cyagen Biosciences, Inc. The cells were positive for the surface markers CD29, CD44 and stem cell antigen-1 (>70\%), and negative for CD117 ( $<5 \%)$. Subsequently, $\sim 3 \times 10^{5}$ cells were cultured in $\alpha$-minimum essential medium (Invitrogen; Thermo Fisher Scientific, Inc.) supplemented with $10 \%$ FBS (Gibco; Thermo Fisher Scientific, Inc.) and 1\% penicillin-streptomycin in a humidified atmosphere with $5 \%$ $\mathrm{CO}_{2}$ at $37^{\circ} \mathrm{C}$ in $25-\mathrm{cm}^{2}$ flasks and 12 -well plates (Wuxi NEST Biotechnology Co., Ltd.). The culture medium was renewed every 2 days for 2 weeks to obtain a confluent monolayer.

Themedium waschanged toosteogenic differentiationmedium supplemented with $10 \%$ FBS, $1 \%$ penicillin-streptomycin, $1 \%$ glutamine, $0.2 \%$ ascorbate, $1 \% \beta$-glycerophosphate and $0.01 \%$ dexamethasone. The cells were incubated for a further 21 days and the medium was renewed every 3 days.

Ti alloy particle preparation. Ti alloy particles $(\sim 4.5 \mu \mathrm{m}$; $0.5 \mathrm{~m}^{2} / \mathrm{mg}$; Zimmer Biomet) were used in the present study. The particles were sterilized at $180^{\circ} \mathrm{C}$ for $45 \mathrm{~min}$, soaked in $95 \%$ ethanol for $48 \mathrm{~h}$ and washed five times in PBS. The Limulus Amebocyte Lysate assay was performed to ensure the particles were free from endotoxin (QCL-1000 Chromogenic LAL; BioWhittaker; Lonza Group, Ltd.) (25). In vitro, the Ti alloy particles $(0.1 \mathrm{mg} / \mathrm{ml})$ were added to $\alpha$-minimum essential medium (Invitrogen; Thermo Fisher Scientific, Inc.) for $24 \mathrm{~h}$, after which the Ti alloy particles appeared to be similar to the wear debris retrieved from peri-prosthetic tissues (23,26-28). For in vivo experiments, $10 \mu \mathrm{l}$ Ti suspension containing $4 \times 10^{4}$ particles of Ti in normal saline was used, which was equivalent to $\sim 4 \times 10^{6}$ particles $(200 \mu \mathrm{g} / \mathrm{ml})(27)$.

Mice and model of aseptic loosening. All animal experiments were approved by the Animal Ethics Committee of Ningxia Medical University (Yinchuan, China) and were performed at the Experimental Animal Center of Ningxia Medical University. Female C57BL/6J mice ( $\mathrm{n}=45$; age, 10 weeks; weight, $20 \pm 2$ g, Experimental Animal Center of Ningxia Medical University, Yinchuan, China) were housed in pressure-controlled ventilation cages at a constant temperature of $25^{\circ} \mathrm{C}$ with $40-70 \%$ humidity and a $12 / 12 \mathrm{~h}$ light/dark cycle, and were fed a normal rodent diet ad libitum.

To establish the model of aseptic loosening, the mice were intraperitoneally anesthetized with Nembutal containing $0.6 \%$ pentobarbital sodium $(40 \mathrm{mg} / \mathrm{kg})$. Then, the tibial plateau was exposed and a canal (diameter, $3 \mathrm{~mm}$ ) was created with a hand drill. Each canal was injected with $10 \mu \mathrm{l}$ Ti alloy particle suspension and implanted with a Ti pin, the head of which was maintained at the same level as the tibial plateau. After the surgery, $20 \mu \mathrm{l}$ Ti particles were injected into the joint capsule every 2 weeks.

Experimental design. Cytotoxicity was first assessed in vitro, and $25 \mu \mathrm{M}$ resveratrol (Sigma-Aldrich; Merck KGaA) was deemed as optimal for maintaining cell viability. Subsequently, the cells were treated with or without Ti alloy particles and resveratrol. After 21 days of osteogenic differentiation, the effects on osteogenesis and the Wnt/ $\beta$-catenin signaling pathway were detected by Alizarin red S staining, western blotting and reverse transcription-quantitative PCR (RT-qPCR). In the in vivo experiments, $15 \mathrm{C} 57 \mathrm{BL} / 6 \mathrm{~J}$ mice 
were used and randomly divided into three groups as follows: Control group (5 mice; 0.1\% DMSO); low dose group (5 mice; $10 \mathrm{mg} / \mathrm{kg}$ resveratrol) and high dose group (5 mice; $30 \mathrm{mg} / \mathrm{kg}$ resveratrol) (29). All the mice were implanted with a Ti pin and drugs were injected intraperitoneally twice per week for 4 weeks $(28,30)$. All the mice were sacrificed with $100 \%$ $\mathrm{CO}_{2}$ (10 1/min; $20 \%$ volume displaced $/ \mathrm{min}$ ); the $\mathrm{CO}_{2}$ flow was maintained until at least $1 \mathrm{~min}$ after the cessation of the animal's breathing and heartbeat, as well as the fading of eye color, in order to ensure animal death. Then, a pullout test of the Ti pin, immunohistochemistry and micro-CT ( $\mu \mathrm{CT})$ were used to analyze the bone formation around the prosthesis.

Cell Counting Kit-8 (CCK-8) assay. Cells $\left(5 \times 10^{3}\right)$ were cultured in a 96-well plate overnight, followed by treatment with $12.5,25,50,75$ and $100 \mu \mathrm{M}$ resveratrol for 24,48 and 72 h. Subsequently, $10 \mu$ l CCK-8 solution (BestBio Co., Ltd.) was added and incubated for $2 \mathrm{~h}$ at $37^{\circ} \mathrm{C}$. For quantitative analysis, the absorbance at $450 \mathrm{~nm}$ was measured using a spectrophotometer (Bio-Rad Laboratories, Inc.).

Caspase-3 assay. To analyze the effect of various concentrations of Ti alloy particles on the apoptosis of BMSCs, $4 \times 10^{6}$ cells were cultured in $60-\mathrm{mm}$ petri dishes with 0.1 , 0.5 and $1 \%$ concentrations of $\mathrm{Ti}$ alloy particles. Based on a previous study (31), the activity of caspase- 3 was measured to assess the levels of apoptosis at 24,48 and $72 \mathrm{~h}$ after the addition of $\mathrm{Ti}$ alloy particles and $\mathrm{Ti}$ alloy particles with resveratrol. Briefly, cells were washed twice in PBS, lysed in $150 \mu 1$ lysis buffer from the caspase-3 colorimetric assay kit (Nanjing KeyGen Biotech Co., Ltd., for $60 \mathrm{~min}$ on ice and then centrifuged at $560 \mathrm{x}$ g for $1 \mathrm{~min}$ at $4^{\circ} \mathrm{C}$. A supernatant sample (50 $\mu \mathrm{l}$ ) was mixed with $50 \mu \mathrm{l}$ reaction buffer and incubated for $4 \mathrm{~h}$ at $37^{\circ} \mathrm{C}$. The absorbance at $405 \mathrm{~nm}$ was measured using a spectrophotometer (Bio-Rad Laboratories, Inc.).

Alizarin red S staining and quantification. BMSCs were cultured in osteogenic differentiation medium for 21 days. The matrix mineralization level was assessed by Alizarin red S staining. The cells were fixed with $10 \%(\mathrm{v} / \mathrm{v})$ formalin at $37^{\circ} \mathrm{C}$ for $15 \mathrm{~min}$. Then, the cells were washed twice with PBS and stained with $1 \mathrm{ml}$ Alizarin red S (pH 4.2; Cyagen Biosciences, Inc.) for $15 \mathrm{~min}$. For quantitation, the stained cells were incubated with $10 \%$ (w/v) cetylpyridinium chloride in $10 \mathrm{mM}$ sodium phosphate buffer ( $\mathrm{pH} 7.0$ ) for $15 \mathrm{~min}$ and the absorbance at $562 \mathrm{~nm}$ was measured.

Western blot analysis. BMSCs were washed with cold PBS and proteins were extracted with RIPA buffer (Sigma-Aldrich; Merck KGaA). Protein concentration was determined using a bicinchoninic acid protein assay kit (Nanjing KeyGen Biotech Co., Ltd.). Protein $(40 \mu \mathrm{g})$ was separated by $10 \%$ SDS-PAGE and transferred to PVDF membranes. Subsequently, the membranes were blocked in 5\% dry skimmed milk at room temperature for $2 \mathrm{~h}$, and incubated overnight at $4^{\circ} \mathrm{C}$ with the following primary antibodies: Anti-Runx2 (cat. no. ab92336; 1:500) and anti-osteocalcin (OCN; cat. no. ab76690; 1:1,000; all Abcam). Secondary antibody (1:2,000; Goat Anti-Rabbit IgG; cat. no. 4970; Cell Signaling Technology, Inc.) was then added to the membranes for $1 \mathrm{~h}$ at room temperature. The membranes were exposed to enhanced chemiluminescence reagent (Nanjing KeyGen Biotech Co., Ltd.). Semi-quantitative analysis of protein bands was performed by a detection system (PerkinElmer, Inc.) and ImageJ software (LI-COR Biosciences, version 1.8.0.112).

$R T-q P C R$. BMSCs $\left(1 \times 10^{5}\right.$ cells/well $)$ were seeded in $60-\mathrm{mm}$ plates. Total RNA was extracted using TRIzol ${ }^{\circledR}$ reagent (Thermo Fisher Scientific, Inc.) and RNA purity was calculated using the 260/280 absorbance ratio (NanoDrop Technologies; Thermo Fisher Scientific, Inc.). First-strand cDNA was synthesized using PrimeScript (Takara Bio, Inc.). qPCR was performed using SYBR ${ }^{\circledR}$ Premix Ex Taq ${ }^{\mathrm{TM}}$ II (Takara Bio Inc.) and the thermocycling conditions were as follows: $95^{\circ} \mathrm{C}$ for $15 \mathrm{~min}$, followed by 40 amplification cycles at $95^{\circ} \mathrm{C}$ for $10 \mathrm{sec}$ and $58^{\circ} \mathrm{C}$ for $30 \mathrm{sec}$, and a final extension at $72^{\circ} \mathrm{C}$ for $30 \mathrm{sec}$. Relative mRNA expression was calculated using the $2^{-\Delta \Delta C q}$ method (32).

The PCR primers used in the present study were as follows: Runx2 forward, 5'-GACTGTGGTTACCGTCATGGC-3' and reverse, 5'-ACTTGGTTTTTCATAACAGCGGA-3'; OCN forward, 5'-CTTGGGTTCTGACTGGGTGT-3' and reverse, 5'-TCTAGCCCTCTGCAGGTCAT-3'; $\beta$-catenin forward, 5'-ACAGGGTGCTATTCCACGAC-3' and reverse, 5'-CTG CACAAACAATGGAATGG-3'; Lef-1 forward, 5'-GCCACC GATGAGATGATCCC-3' and reverse, 5'-TTGATGTCGGCT AAGTCGCC-3'; transcription factor (Tcf)-4 forward, 5'-ATG GCCCAAGTAGTGATGTCT-3' and reverse, 5'-CAAACA CGTCGGTCTCATACA-3'; and GAPDH forward, 5'-TGA TGACATCAAGAAGGTGGTGAA-3' and reverse, 5'-TCC TTGGAGGCCATGTAGGCCAT-3'.

Immunohistochemistry examination. The tibia samples were fixed in $4 \%$ paraformaldehyde and EDTA for $24 \mathrm{~h}$ at $4^{\circ} \mathrm{C}$. After dehydration in ethanol, the samples were embedded in paraffin at $60^{\circ} \mathrm{C}$ and cut into $5-\mu \mathrm{m}$ sections using the RM2235 Rotary Microtome Basic instrument (Leica Microsystems, Inc.). To observe the expression levels of Runx2, the glass slides were added to an autoclave for $2 \mathrm{~min}$, cooled for $20 \mathrm{~min}$, and then incubated at $23^{\circ} \mathrm{C}$ for $10 \mathrm{~min}$ with $3 \%$ hydrogen peroxide. Following washing with PBS, primary antibody against Runx2 (cat. no. ab92336; 1:300; Abcam) was added and incubated overnight at $4^{\circ} \mathrm{C}$. Subsequently, the slides were incubated with secondary antibodies (1:1,000; Enzyme-labeled goat anti-rabbit IgG polymer; cat. no. SSA018; Sino Biological). The results were obtained using a microscopic imaging system (DM2000 LED; Leica Microsystems, Inc.) and Image-Pro Plus 6.0 software (Media Cybernetics, Inc.).

Pullout test to assess Ti prosthesis steadiness. After sacrificing the mice, the soft tissues around the tibia were carefully removed and the head of the Ti pin was exposed. Each tibia was fixed to a special clamp, aligning the long axis of the pin with the long axis of the test machine (HP-100 Control Electronic Universal Testing machine; Yueqing Zhejiang Instrument Scientific Co., Ltd.). Then, the HP-100 device was used to pull the Ti pin out of the tibia at a rate of $2 \mathrm{~mm} / \mathrm{min}$. The load values were automatically measured by software (Edburg software Version 1.0; Yueqing ALIYIQI Instrument Co., Ltd.). 
$\mu C T$ scanning. The mouse tibia samples were scanned by $\mu \mathrm{CT}$ (SkyScan 1176; Bruker Corporation). Each tibia sample (without soft tissues) was fixed in $4 \%$ paraformaldehyde at $4^{\circ} \mathrm{C}$ for 4 weeks and the tomographic scans were acquired at $900 \mathrm{~ms}$ exposure time, $45 \mathrm{~kW}$ voltage and $550 \mathrm{~mA}$ current. The bone volume (BV), bone volume fraction (BV/TV), trabecular thickness (Tb.Th), trabecular number (Tb.N) and specific bone surface $(\mathrm{BS} / \mathrm{BV})$ of the shin bone surrounding the prosthesis were automatically detected by NRecon software (version 1.1.11; Bruker Corporation).

Statistical analysis. The results are presented as the mean $\pm \mathrm{SD}$ $(n=3)$. One-way ANOVA and Dunnett was used to compare multiple groups. SPSS v19.0 (IBM Corp.) was used for statistical analyses. Graphs were prepared using GraphPad Prism (version 6.0 for Windows; GraphPad Software, Inc.). $\mathrm{P}<0.05$ was considered to indicate a statistically significant difference.

\section{Results}

Effect of various doses of resveratrol on the viability of BMSCs in vitro. First, the viability of BMSCs treated with resveratrol was investigated in vitro. Following treatment with $12.5,25$, 50, 75 and $100 \mu \mathrm{M}$ resveratrol, cell viability was detected using a CCK-8 assay (Fig. 1A). The results demonstrated that treatment with $25 \mu \mathrm{M}$ resveratrol effectively enhanced cell viability at $24 \mathrm{~h}(1.188 \pm 0.049 \mathrm{in}$ the control group, $1.645 \pm 0.136$ in the $25 \mu \mathrm{M}$ resveratrol group and $1.376 \pm 0.047$ in the $50 \mu \mathrm{M}$ resveratrol group; $\mathrm{P}<0.05$; Fig. 1A). However, no difference was observed among the groups at $48 \mathrm{~h}$, and the groups treated with 25 and $50 \mu \mathrm{M}$ resveratrol exhibited a statistically significant decrease in cell viability at $72 \mathrm{~h}(1.270 \pm 0.015$ in the control group, $1.184 \pm 0.031$ in the $25 \mu \mathrm{M}$ resveratrol group and $1.177 \pm 0.029$ in the $50 \mu \mathrm{M}$ resveratrol group; $\mathrm{P}<0.05$; Fig. 1A). Therefore, $25 \mu \mathrm{M}$ resveratrol was used in subsequent experiments to avoid cytotoxicity.

Resveratrol increases osteogenesis and stimulates the Wnt/ $\beta$-catenin signaling pathway. Osteogenesis was evaluated by Alizarin red S staining and quantification. The osteogenic differentiation of BMSCs was significantly decreased in the presence of Ti alloy particles $(3.18 \pm 0.09$ in the control group vs. $1.47 \pm 0.08$ in the $\mathrm{Ti}$ alloy particles group; $\mathrm{P}<0.01$; Fig. 1B and C). However, following treatment with resveratrol, bone formation inhibition by $\mathrm{Ti}$ particles was reversed (3.18 \pm 0.09 in the control group vs. $3.33 \pm 0.05$ in the resveratrol with Ti alloy particles group; $\mathrm{P}=0.24$; Fig. $1 \mathrm{~B}$ and $\mathrm{C}$ ).

The results of western blotting (Fig. 2A-C) revealed that Runx2 expression was significantly increased after treatment with Ti alloy particles $(0.072 \pm 0.006$ in the control group vs $0.128 \pm 0.002$ in the Ti alloy particles group; $\mathrm{P}<0.01$; Fig. $2 \mathrm{~B}$ ) Compared with the control group, the expression levels of Runx 2 were markedly increased in the resveratrol with $\mathrm{Ti}$ alloy particles group. Similarly, the expression levels of OCN were increased in the resveratrol with Ti alloy particles group $(0.102 \pm 0.014$ in the control group vs. $0.276 \pm 0.030$ in the $\mathrm{Ti}$ alloy particles group; $\mathrm{P}<0.01$; Fig. $2 \mathrm{C}$ ).

RT-PCR analysis revealed similar results (Fig. 2D). Compared with the control group, the expression levels of Runx2 $(1.03 \pm 0.09$ in the control group vs. $1.51 \pm 0.12$ in the
Ti alloy particles group; $\mathrm{P}<0.05)$ and $\mathrm{OCN}(1.03 \pm 0.17$ in the control group vs. $2.17 \pm 0.09$ in the Ti alloy particles group; $\mathrm{P}<0.01)$ were increased in the Ti alloy particles group (Fig. 2D) and in the resveratrol with Ti alloy particles group (Runx2, $1.03 \pm 0.09$ in the control group vs. $9.34 \pm 0.23$ in the resveratrol with Ti alloy particles group, $\mathrm{P}<0.01$; OCN, $1.03 \pm 0.17$ in the control group vs. $4.06 \pm 0.06$ in the resveratrol with $\mathrm{Ti}$ alloy particles group, $\mathrm{P}<0.01$ ). However, these results did not completely match the results of the staining analysis.

To determine the effect of resveratrol with Ti alloy particles on the Wnt/ $\beta$-catenin signaling pathway, the present study further examined the mRNA expression levels of Lef-1, Tcf-4 and $\beta$-catenin (Fig. 2D). The results demonstrated that the expression levels of Lef- 1 and Tcf- 4 were significantly increased in the $\mathrm{Ti}$ alloy particles group $(1.03 \pm 0.04$ vs. $1.72 \pm 0.07$ and $0.97 \pm 0.06$ vs. $2.14 \pm 0.10$, respectively; both $\mathrm{P}<0.01)$ and in the resveratrol with $\mathrm{Ti}$ alloy particles group $(1.03 \pm 0.04$ vs. $8.14 \pm 0.27$ and $0.97 \pm 0.06$ vs. $10.42 \pm 0.25$, respectively; both $\mathrm{P}<0.01)$. However, $\beta$-catenin expression was only increased in the resveratrol with $\mathrm{Ti}$ alloy particles group $(1.03 \pm 0.19$ vs. $6.76 \pm 0.09 ; \mathrm{P}<0.01)$. These results demonstrated that resveratrol may inhibit the osteolysis induced by $\mathrm{Ti}$ alloy particles via activation of the $\mathrm{Wnt} / \beta$-catenin signaling pathway.

In addition, since the RT-qPCR results revealed that the expression levels of Runx 2 and OCN were increased in the Ti-alloy particles group, apoptosis was examined by assessing caspase-3 activity at 24, 48 and $72 \mathrm{~h}$ after the addition of Ti alloy particles. Compared with the control group, apoptosis was markedly increased, particularly with 0.5 and $1 \%$ Ti alloy particles (Fig. 2E). Subsequently, the levels of caspase-3 were measured after treatment with resveratrol, and the results demonstrated that resveratrol markedly decreased the caspase-3 levels compared with the Ti alloy particles group (Fig. 2F).

Resveratrol enhances bone microstructure around the prosthesis. To investigate the effects of resveratrol on bone formation in vivo, a mouse model of aseptic loosening was established (Fig. 3A and B). Subsequently, pullout tests of the Ti pins, immunohistochemistry and $\mu \mathrm{CT}$ scans were used to analyze the differences in the bone microstructure among the control, low-dose and high-dose groups. The results of the pullout test of Ti pins (Fig. 3C) demonstrated that, compared with the control group $(1.57 \pm 0.16 \mathrm{~N})$, the pulling load was significantly increased after treatment with resveratrol, particularly in the high-dose group (low dose resveratrol group, 9.87 $\pm 0.39 \mathrm{~N}, \mathrm{P}<0.01$; high dose resveratrol group, $14.33 \pm 0.68 \mathrm{~N} ; \mathrm{P}<0.01)$. In addition, the difference in pulling load between the low- and high-dose resveratrol groups was statistically significant $(\mathrm{P}<0.01)$.

The expression levels of Runx 2 in the bone around the prosthesis are shown in Fig. 3D and F. Compared with the control group $(0.427 \pm 0.023)$, the expression levels of Runx2 were significantly increased in the low- and high-dose resveratrol groups (low-dose resveratrol, $0.610 \pm 0.017, \mathrm{P}<0.01$; high-dose resveratrol, $0.740 \pm 0.025 ; \mathrm{P}<0.01)$. This effect was more pronounced in the high-dose resveratrol group compared with in the low-dose group $(0.740 \pm 0.025$ vs. $0.610 \pm 0.017$, respectively; $\mathrm{P}<0.05)$.

The $\mu \mathrm{CT}$ scan and quantification analysis demonstrated analogous results (Fig. 3E and G). Compared with the control 
A

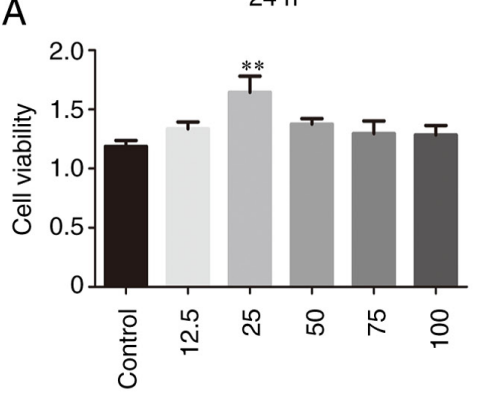

$48 \mathrm{~h}$

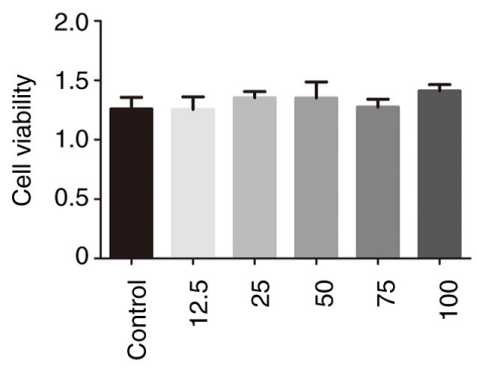

B
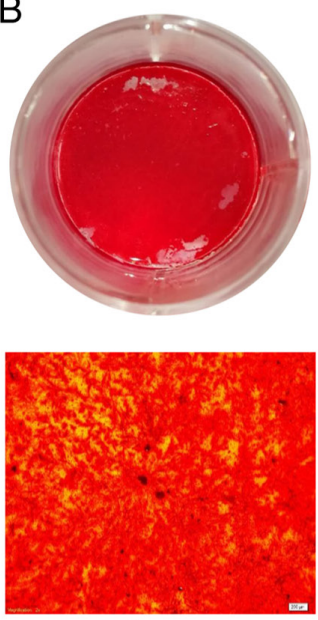

Control
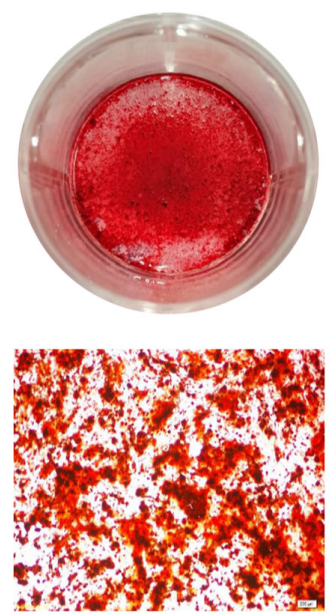

Ti $1 \%$
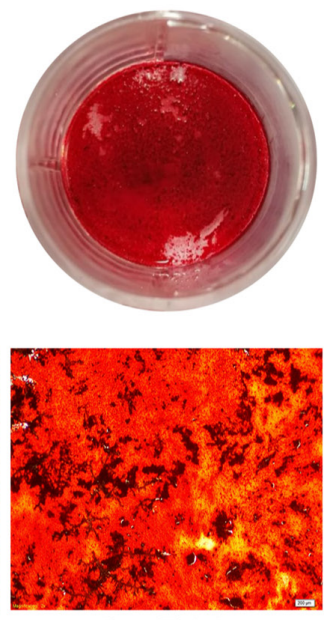

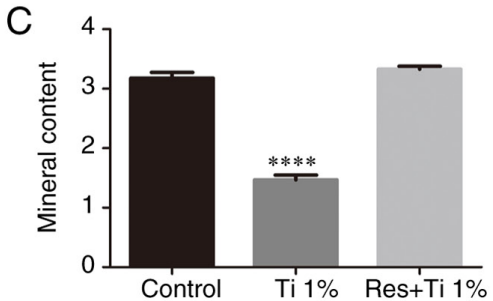

Figure 1. Resveratrol enhances the viability and osteogenic differentiation of BMSCs in vitro. (A) BMSCs treated with $0-100 \mu \mathrm{M}$ resveratrol for $24-72 \mathrm{~h}$ were analyzed by the Cell Counting Kit-8 assay. (B) Alizarin red S staining and (C) quantitative analysis of calcified matrix in Ti alloy-particles with or without resveratrol compared with control group. Data represent mean $\pm 95 \%$ confidence interval. ${ }^{*} \mathrm{P}<0.05,{ }^{* *} \mathrm{P}<0.01$ and ${ }^{* * * * *} \mathrm{P}<0.0001$ vs. the control group; $\mathrm{n}=3$. BMSCs, bone marrow stem cells; Res, resveratrol; Ti, titanium alloy-particles.

group $\left(0.109 \pm 0.004 \mathrm{~mm}^{3}\right), \mathrm{BV}$ was significantly increased following treatment with a low dose $\left(0.129 \pm 0.004 \mathrm{~mm}^{3}\right.$; $\mathrm{P}<0.01)$ and a high dose of resveratrol $\left(0.156 \pm 0.008 \mathrm{~mm}^{3}\right.$; $\mathrm{P}<0.01)$ in a dose-dependent manner $(\mathrm{P}=0.032)$. Similarly, compared with the control group $(11.71 \pm 0.416 \%), \mathrm{BV} / \mathrm{TV}$ was increased in the low-dose $(13.52 \pm 0.393 \% ; \mathrm{P}<0.05)$ and the high-dose $(15.62 \pm 0.430 \%$; $\mathrm{P}<0.01)$ resveratrol groups in a dose-dependent manner $(\mathrm{P}=0.023)$. By contrast, compared with the control group $\left(76.32 \pm 2.20^{1} / \mathrm{mm}\right), \mathrm{BS} / \mathrm{BV}$ was significantly decreased in the resveratrol groups (low-dose resveratrol, $64.98 \pm 2.18^{1} / \mathrm{mm}, \mathrm{P}<0.05$; low-dose resveratrol, $\left.58.03 \pm 1.62^{1} / \mathrm{mm} ; \mathrm{P}<0.01\right)$. Additionally, Tb.Th and Tb.N were increased following treatment with resveratrol, but this increase was only significant in the high-dose group (Tb.Th, $0.041 \pm 0.002$ vs. $0.047 \pm 0.001 \mathrm{~mm}$, respectively; $\mathrm{P}<0.05$; Tb.N, $2.841 \pm 0.126$ vs. $3.253 \pm 0.078^{1} / \mathrm{mm}$, respectively; $\mathrm{P}<0.05$ ).

\section{Discussion}

Joint arthroplasty is an effective and reliable treatment method for osteoarthritis, and this surgery may effectively restore joint function and control pain. However, following surgery, aseptic loosening of prosthetic joints remains an inevitable long-term complication and affects the success rate of joint replacement (9). Although previous studies have reported that an imbalance between osteogenesis and osteolysis around the prosthesis is the key factor in aseptic loosening, the pathogenesis of osteolysis remains unclear and effective therapeutic drugs have not yet been developed (33).

Resveratrol has been demonstrated to have various biological functions, including inhibition of inflammation (34), attenuation of apoptosis in cardiomyocytes (35) and promotion of cell longevity (36). In the present study, 25 and $50 \mu \mathrm{M}$ resveratrol effectively increased the cell proliferation capacity at $24 \mathrm{~h}$; however, at $72 \mathrm{~h}$, the cell proliferation capacity decreased in a dose-related manner. Rubiolo et al reported that resveratrol induced cell arrest in the G0-G1 phase but not in the S-phase in rat hepatocytes. In addition, following treatment with 50 and $100 \mu \mathrm{M}$ resveratrol for 24, 48 and $72 \mathrm{~h}$, the number of cells in the S-phase was increased, but in contrast, the cells in G0-G1 and G2-M phases was decreased (37). Moreover, in the current study, Ti alloy particles markedly inhibited the osteogenic differentiation of BMSCs; however, following treatment with resveratrol, osteolysis caused by Ti alloy particles was inhibited. Similarly, Matsuda et al (38) reported that resveratrol prevents trauma from occlusion-induced alveolar bone loss by suppressing osteoclast differentiation. Therefore, it may be inferred that resveratrol may prevent osteoclast formation and promote osteogenic differentiation. However, the results of western blotting and RT-PCR indicated that Ti-alloy particles increased the expression of osteogenesis-related factors, such as Runx2, which is not the same as the results obtained from Alizarin red S staining. Therefore, the level of 

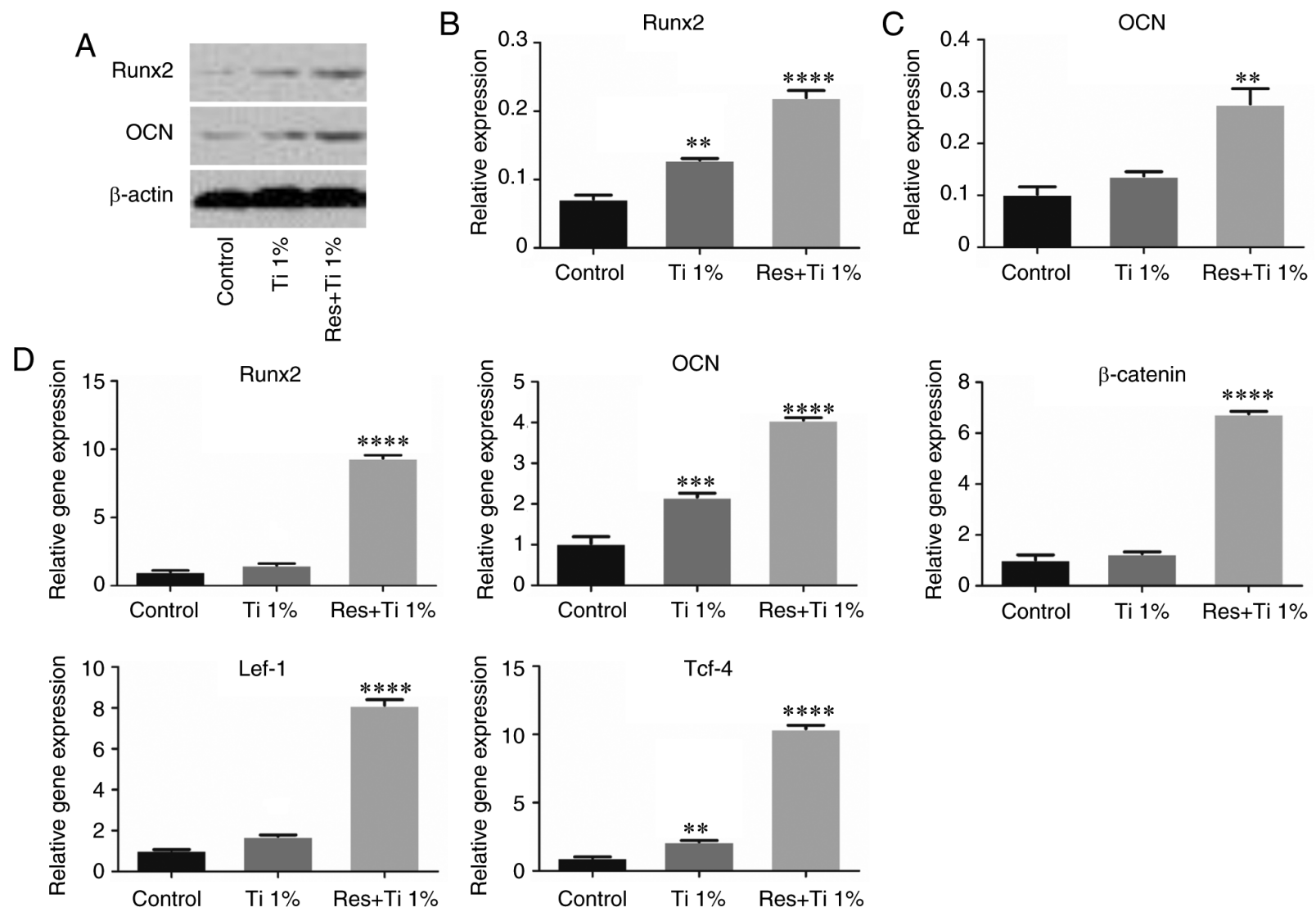

$\mathrm{E}$
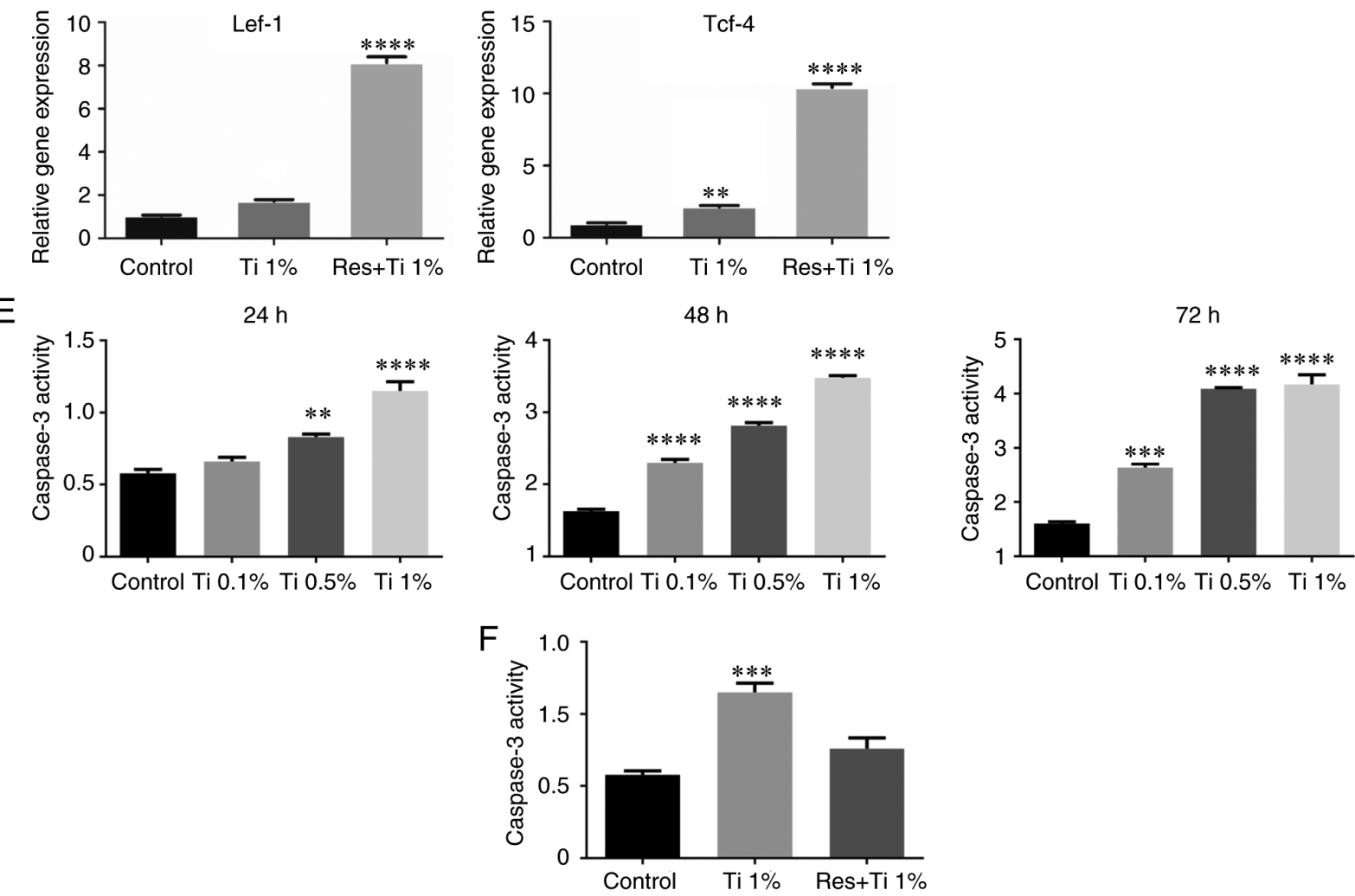

Figure 2. Resveratrol regulates osteogenic differentiation in BMSCs treated with Ti alloy-particles via the Wnt/ $\beta$-catenin pathway. (A-C) Western blotting was used to determine the Runx2 and OCN protein levels in BMSCs by treated with resveratrol and Ti alloy-particles after 21 days of osteoinduction. (D) Reverse transcription-PCR was used to analyze the mRNA levels of Runx2, OCN, $\beta$-catenin, Lef- 1 and Tcf-4 in BMSCs after 21 days of osteogenic differentiation. (E) Caspase-3 activity assay was performed to determine the level of apoptosis in BMSCs treated with Ti alloy-particles. (F) After treatment with Ti alloy particles and Resveratrol, the level of apoptosis in BMSCs was determined by Caspase-3 activity. ${ }^{* *} \mathrm{P}<0.01,{ }^{* * * *} \mathrm{P}<0.001$ and ${ }^{* * * * *} \mathrm{P}<0.0001$ vs. the control group $\mathrm{n}=3$. BMSCs, bone marrow stem cells; Lef-1, lymphoid enhancer binding factor 1; OCN, osteocalcin; Res, resveratrol; Runx2, runt-related transcription factor 2; Tcf-4, transcription factor 4; Ti, Titanium alloy-particles.

apoptosis of BMSCs was further examined, and the results demonstrated that, with the increase in the concentration of Ti-alloy particles, their apoptosis-inducing effect became more prominent, particularly at concentrations of 0.5 and $1 \%$. In addition, resveratrol effectively reduced the pro-apoptotic effect of Ti-alloy particles on cells. These results revealed that, although Ti-alloy particles can stimulate the expression of osteogenic factors in BMSCs, their effect on cell apoptosis is more prominent. In addition, resveratrol was shown to effectively reduce the effect of Ti-alloy particles on apoptosis, indicating that it may be of value in preventing Ti-alloy particle-induced osteolysis.

Following treatment with resveratrol, the expression levels of Runx2 and OCN were upregulated. In addition, the results of RT-qPCR revealed that the mRNA expression levels of $\beta$-catenin, Lef- 1 and Tcf- 4 were increased, suggesting that resveratrol 
A
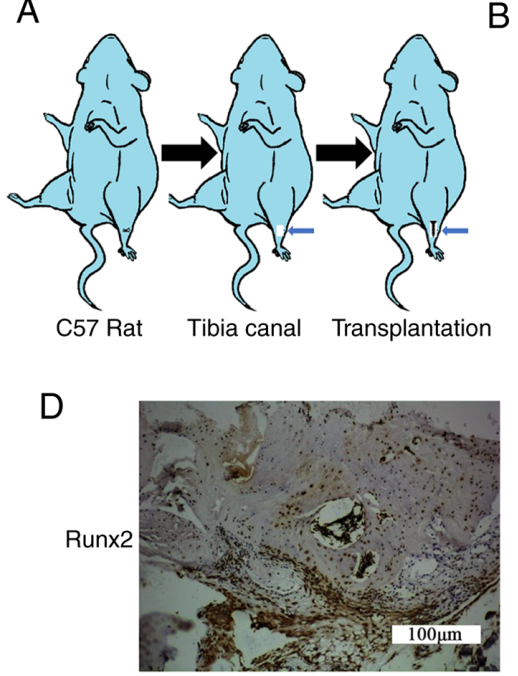

E

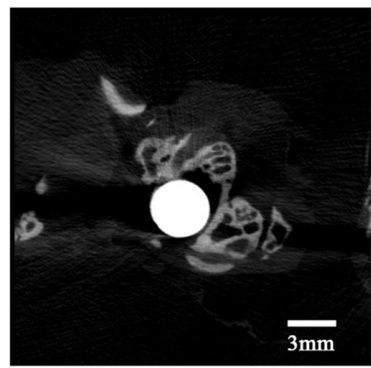

Control
B
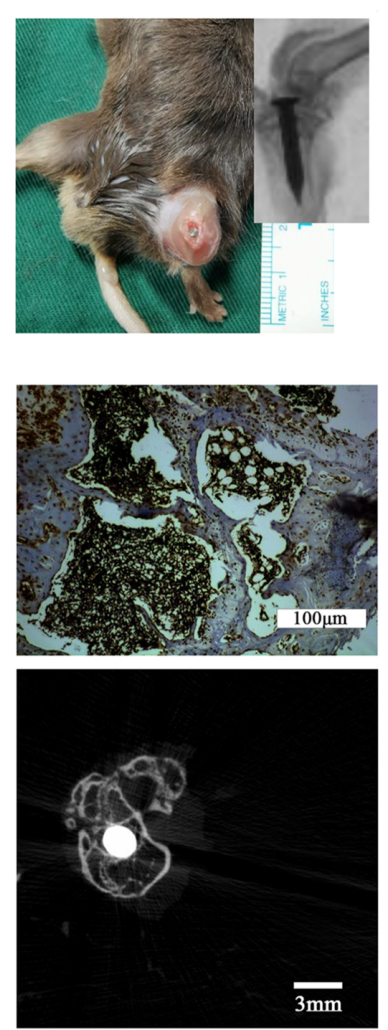

Low dose Res
C
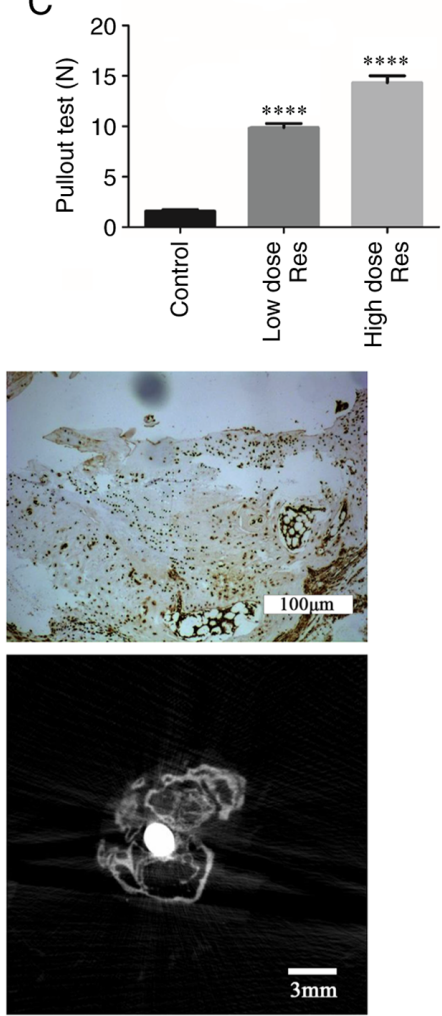

High dose Res
F
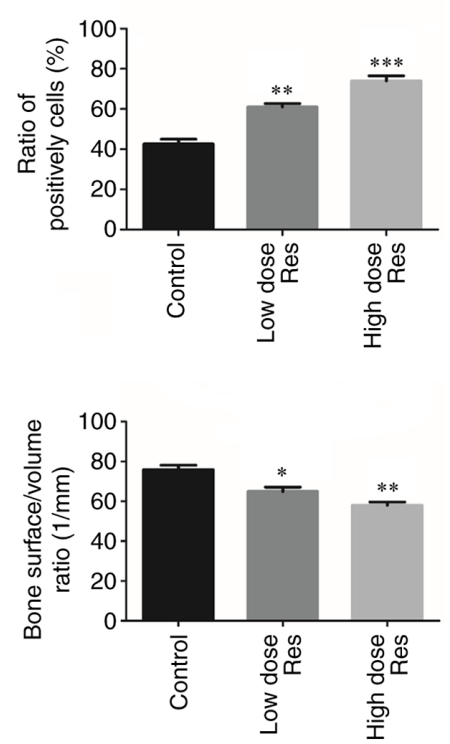

G
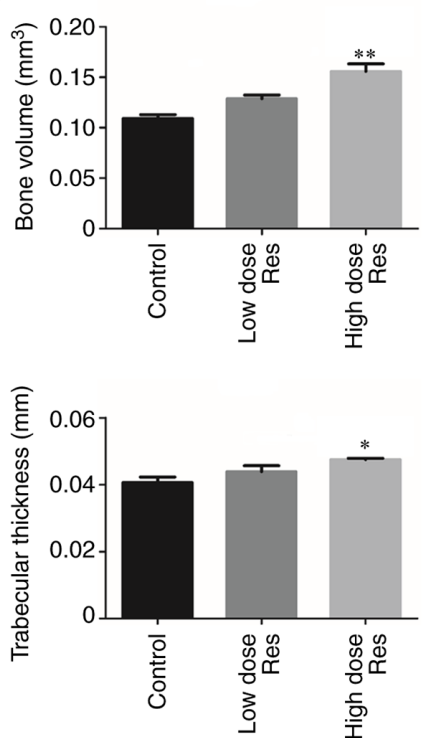
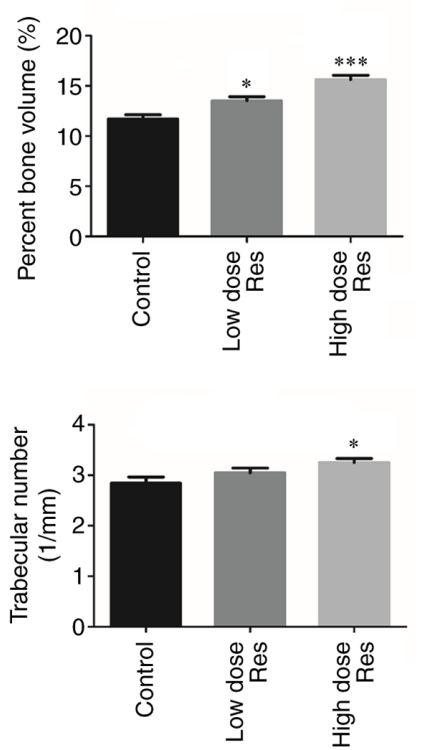

Figure 3. Resveratrol enhances bone formation around the prosthesis in vivo. (A) Schematic drawing of the transplantation procedure. (B) Establishment of the model of aseptic loosening. (C) Pulling force required to remove the titanium pin implant from the tibia with or without resveratrol. (D-G) Immunohistochemistry and $\mu \mathrm{CT}$ were used to determine the effects of resveratrol on bone formation. (D and F) Immunohistochemical staining and semi-quantification of Runx2 protein expression levels in periprosthetic tissues. The ratios of the number of cells positively stained for Runx 2 to the total number of cells were plotted. Scale bar, $100 \mu \mathrm{m}$. (E and G) Cross-sectional images of titanium implants and bone microstructure analyzed by $\mu \mathrm{CT}$ scans (Scale bar, 3 mm); the bone volume, percentage bone volume, bone surface density, trabecular thickness and trabecular number were calculated. ${ }^{*} \mathrm{P}<0.05,{ }^{* *} \mathrm{P}<0.01,{ }^{* * * *} \mathrm{P}<0.001$ and ${ }^{* * * * *} \mathrm{P}<0.001 \mathrm{vs}$. the control group $(\mathrm{n}=3) . \mu \mathrm{CT}$, micro-CT; Res, resveratrol; Runx2, runt-related transcription factor 2.

may enhance the osteogenic differentiation of BMSCs via the Wnt/ $\beta$-catenin signaling pathway. Of note, Ti alloy particles have already been reported to exert an inhibitory effect on osteogenic differentiation (39). The results of the present study also demonstrated that osteogenesis was inhibited by Ti alloy particles. However, the expression levels of Runx2 and OCN were upregulated in the presence of Ti alloy particles. These results suggested that the particles enhanced osteogenesis, which was inconsistent with the observations following Alizarin red $\mathrm{S}$ staining. In agreement with a previous study, the Ti particles 
may stimulate osteogenesis in human BMSCs (40), suggesting that Ti particles do not directly inhibit the process of osteogenic differentiation, but may rather affect cell viability (41).

Another aim of the present study was to determine the effect of resveratrol on bone formation in mice with periprosthetic osteolysis. Following treatment with resveratrol, the pulling force of the Ti pin removed from the tibia was increased in a dose-dependent manner. This finding supports the hypothesis that resveratrol may decrease bone resorption. Similarly, others have reported that Sirt1, which is activated by resveratrol, may inhibit aseptic loosening via NF- $\kappa \mathrm{B}$ deacetylation (42). In addition, $\mu \mathrm{CT}$ scanning demonstrated that $\mathrm{BV}$ and $\mathrm{BV} / \mathrm{TV}$ in the periprosthetic tissue were markedly enhanced in a dose-dependent manner. $\mathrm{BS} / \mathrm{BV}$ also indicated an anti-osteolytic effect of resveratrol in mice; however, this was not dose-dependent. Additionally, there were marked differences in Tb.Th and Tb.N between the high-dose resveratrol and the control groups, although no significant differences were observed between the low-dose resveratrol and control groups. These findings support the hypothesis that resveratrol is able to enhance the $\mathrm{BV}, \mathrm{BS} / \mathrm{BV}$, BV/TV, Tb.N and Tb.Th in cases with aseptic loosening induced by wear particles, which suggests that resveratrol may inhibit bone resorption. In accordance with the aforementioned findings, Lee et al (43) demonstrated that BV was markedly increased following treatment with resveratrol. Furthermore, the results of immunohistochemistry demonstrated that resveratrol increased the expression levels of Runx 2 in a dose-dependent manner. These findings suggest a key role of resveratrol in inhibiting osteolysis by upregulating Runx 2 expression in an model of aseptic loosening (44). Furthermore, it should be noted that osteoclasts must also be investigated in subsequent studies. Specifically, co-culture of osteoblast with RAW 264.7 cells may explain why the expression levels of Runx 2 and OCN were increased in the presence of Ti alloy particles, while osteogenesis was inhibited (45). In addition, the Wnt/ $/$-catenin signaling pathway was not directly targeted in order to demonstrate its role in the protective effects of resveratrol against particle-associated osteolysis, which is another limitation of the present study.

In conclusion, resveratrol effectively inhibited wear particle-associated osteolysis in vivo and in vitro. In addition, resveratrol upregulated Runx 2 and OCN expression, suggesting that resveratrol may be a potential therapeutic agent for the treatment of aseptic loosening of joint prostheses.

\section{Acknowledgements}

The authors would like to thank Dr Mao Mao (General Hospital of Ningxia Medical University) for his technological help.

\section{Funding}

The present study was supported by the Ningxia Natural Science Foundation of China (grant no. NZ17137).

\section{Availability of materials and data}

The datasets used and/or analyzed during the current study are available from the corresponding author on reasonable request.

\section{Authors' contributions}

$\mathrm{XC}$ and QJ conceived the experiments, $\mathrm{XC}$ and TG conducted the experiments and wrote the revised manuscript, SS and XF conducted the experiments, and ShZ, SiZ and YG analyzed the results. XC and QJ confirm the authenticity of all the raw data. All the authors reviewed the manuscript. All the authors have read and approved the final manuscript.

\section{Ethics approval and consent to participate}

The experimental protocol in the present study was conducted in accordance with the National Institutes of Health guidelines for the care and use of laboratory animals and was approved by the Ethics Committee of the General Hospital of Ningxia Medical University (approval no. NXYKDX.2019.722-35, Yinchuan, China).

\section{Patient consent for publication}

Not applicable.

\section{Competing interests}

The authors declare that they have no competing interests.

\section{References}

1. Wang ML, Sharkey PF and Tuan RS: Particle bioreactivity and wear-mediated osteolysis. J Arthroplasty 19: 1028-1038, 2004.

2. Lee SS, Sharma AR, Choi BS, Jung JS, Chang JD, Park S, Salvati EA, Purdue EP, Song DK and Nam S: The effect of TNFa secreted from macrophages activated by titanium particles on osteogenic activity regulated by WNT/BMP signaling in osteoprogenitor cells. Biomaterials 33: 4251-4263, 2012.

3. Yang H, Xu Y, Zhu M, Gu Y, Zhang W, Shao H, Wang Y, Ping Z, Hu X, Wang L and Geng D: Inhibition of titanium-particle-induced inflammatory osteolysis after local administration of dopamine and suppression of osteoclastogenesis via D2-like receptor signaling pathway. Biomaterials 80: 1-10, 2016.

4. Rao AJ, Gibon E, Ma T, Yao Z, Smith RL and Goodman SB: Revision joint replacement, wear particles, and macrophage polarization. Acta Biomater 8: 2815-2823, 2012.

5. Vermes C, Chandrasekaran R, Jacobs JJ, Galante JO, Roebuck KA and Glant TT: The effects of particulate wear debris, cytokines, and growth factors on the functions of MG-63 osteoblasts. J Bone Joint Surg Am 83: 201-211, 2001.

6. Liu X, Zhu S, Cui J, Shao H, Zhang W, Yang H, Xu Y, Geng D and $\mathrm{Yu}$ L: Strontium ranelate inhibits titanium-particle-induced osteolysis by restraining inflammatory osteoclastogenesis in vivo. Acta Biomaterialia 10: 4912-4918, 2014.

7. Guo H, Zhang J, Hao S and Jin Q: Adenovirus-mediated small interfering RNA targeting tumor necrosis factor- $\alpha$ inhibits titanium particle-induced osteoclastogenesis and bone resorption. Int J Mol Med 32: 296-306, 2013.

8. Squillaro T, Peluso G and Galderisi U: Clinical trials with mesenchymal stem cells: An update. Cell Transplant 25: 829-848, 2016.

9. Reginster JY, Brandi ML, Cannata-Andia J, Cooper C, Cortet B, Feron JM, Genant H, Palacios S, Ringe JD and Rizzoli R: The position of strontium ranelate in today's management of osteoporosis. Osteoporos Int 26: 1667-1671, 2015.

10. Karakan NC, Akpinar A, Göze F and Poyraz Ö: Investigating the effects of systemically administered strontium ranelate on alveolar bone loss histomorphometrically and histopathologically on experimental periodontitis in rats. J Periodontol 88: e24-e31, 2017.

11. Baur JA, Pearson KJ, Price NL, Jamieson HA, Lerin C, Kalra A, Prabhu VV, Allard JS, Lopez-Lluch G, Lewis K, et al: Resveratrol improves health and survival of mice on a high-calorie diet. Nature 444: 337-342, 2006. 
12. Baur JA and Sinclair DA: Therapeutic potential of resveratrol: The in vivo evidence. Nat Rev Drug Discov 5: 493-506, 2006.

13. Liu B, Ghosh S, Yang X, Zheng H, Liu X, Wang Z, Jin G, Zheng B, Kennedy BK, Suh Y, et al: Resveratrol rescues SIRT1-dependent adult stem cell decline and alleviates progeroid features in laminopathy-based progeria. Cell Metab 16: 738-750, 2012.

14. Shakibaei M, Shayan P, Busch F, et al: Resveratrol mediated modulation of Sirt-1/Runx2 promotes osteogenic differentiation of mesenchymal stem cells: potential role of Runx 2 deacetylation. PLoS One 7: e35712, 2012.

15. Zhang H, Zhang H, Zhang Y, Ng SS, Ren F, Wang Y, Duan Y, Chen L, Zhai Y, Guo Q and Chang Z: Dishevelled-DEP domain interacting protein (DDIP) inhibits Wnt signaling by promoting TCF4 degradation and disrupting the TCF4/beta-catenin complex. Cell Signal 22: 1753-1760, 2010.

16. Gao X, Ge J, Li W, Zhou W and Xu L: Lncrna kenqlotl promotes osteogenic differentiation to relieve osteolysis via wnt/ $\beta$-catenin activation. Cell Biosci 8: 19, 2018

17. Goessling W, North TE, Loewer S, Lord AM, Lee S, Stoick-Cooper CL, Weidinger G, Puder M, Daley GQ, Moon RT and Zon LI: Genetic interaction of PGE2 and Wnt signaling regulates developmental specification of stem cells and regeneration. Cell 136: 1136-1147, 2009.

18. Komiya $\mathrm{Y}$ and Habas R: Wnt signal transduction pathways. Organogenesis 4: 68-75, 2008.

19. Jing H, Su X, Gao B, et al: Epigenetic inhibition of Wnt pathway suppresses osteogenic differentiation of BMSCs during osteoporosis. Cell Death Dis 9: 176, 2018.

20. Lucero CM, Vega OA, Osorio MM, Tapia JC, Antonelli M Stein GS, van Wijnen AJ and Galindo MA: The cancer-related transcription factor Runx 2 modulates cell proliferation in human osteosarcoma cell lines. J Cell Physiol 228: 714-723, 2013.

21. Komori T, Yagi H, Nomura S, Yamaguchi A, Sasaki K, Deguchi K, Shimizu Y, Bronson RT, Gao YH, Inada M, et al: Targeted disruption of Cbfa1 results in a complete lack of bone formation owing to maturational arrest of osteoblasts. Cell 89: 755-764, 1997.

22. Simic P, Zainabadi K, Bell E, Sykes DB, Saez B, Lotinun S, Baron R, Scadden D, Schipani E and Guarente L: SIRT1 regulates differentiation of mesenchymal stem cells by deacetylating beta-catenin. EMBO Mol Med 5: 430-440, 2013.

23. Yang S, Yu H, Gong W, Wu B, Mayton L, Costello R and Wooley PH: Murine model of prosthesis failure for the long term study of aseptic loosening. J Orthop Res 25: 603-611, 2007.

24. Geng D, Xu Y, Yang H, Wang J, Zhu X, Zhu G and Wang X: Protection against titanium particle induced osteolysis by cannabinoid receptor 2 selective antagonist. Biomaterials 31 1996-2000, 2010.

25. Clohisy JC, Hirayama T, Frazier E, Han SK and Abu-Amer Y NF-kB signaling blockade abolishes implant particle-induced osteoclastogenesis. J Orthop Res 22: 13-20, 2004.

26. von Knoch M, Jewison DE, Sibonga JD, Sprecher C, Morrey BF, Loer F, Berry DJ and Scully SP: The effectiveness of polyethylene versus titanium particles in inducing osteolysis in vivo. J Orthop Res 22: 237-243, 2004.

27. Gu Z, Chu L and Han Y: Therapeutic effect of resveratrol on mice with depression. Exp Ther Med 17: 3061-3064, 2019.

28. Chen HY, Lin PH, Shih YH, Wang KL, Hong YH, Shieh TM, Huang TC and Hsia SM: Natural antioxidant resveratrol suppresses uterine fibroid cell growth and extracellular matrix formation in vitro and in vivo. Antioxidants (Basel) 8: 99, 2019.

29. Grewal AK, Singh N and Singh TG: Effects of resveratrol postconditioning on cerebral ischemia in mice: Role of the sirtuin-1 pathway. Can J Physiol Pharmacol 97: 1094-1101, 2019.
30. Bourne RB, Laskin RS and Guerin JS: Ten-year results of the first 100 genesis II total knee replacement procedures. Orthopedics 30 (Suppl 8): S83-S85, 2007.

31. Zhu YY, Wang ZJ, Ma N and Zhou JW: Proliferation and apoptosis of lung cancer cells regulated by gultaredoxin 3 . Zhonghua Zhong Liu Za Zhi 40: 325-329, 2018 (In Chinese).

32. Livak KJ and Schmittgen TD: Analysis of relative gene expression data using real-time quantitative PCR and the 2(-Delta Delta C(T)) method. Methods 25: 402-408, 2001

33. Rybchyn MS, Slater M, Conigrave AD and Mason RS: An Akt-dependent increase in canonical Wnt signaling and a decrease in sclerostin protein levels are involved in strontium ranelate-induced osteogenic effects in human osteoblasts. J Biol Chem 286: 23771-23779, 2011.

34. Xie J,Zhang $X$ and Zhang L: Negative regulation of inflammation by SIRT1. Pharmacol Res 67: 60-67, 2013.

35. Zhang C, Feng Y, Qu S, Wei X, Zhu H, Luo Q, Liu M, Chen G and Xiao X: Resveratrol attenuates doxorubicin-induced cardiomyocyte apoptosis in mice through SIRT1-mediated deacetylation of p53. Cardiocasc Res 90: 538-545, 2011.

36. Kaeberlein M, McVey M and Guarente L: The SIR2/3/4 complex and SIR2 alone promote longevity in Saccharomyces cerevisiae by two different mechanisms. Genes Dev 13 2570-2580, 1999.

37. Rubiolo JA, López-Alonso H, Martín-Vázquez V, Fol-Rodríguéz N, Vieytes MR and Vega FV: Resveratrol inhibits proliferation of primary rat hepatocytes in G0/G1 by inhibiting DNA synthesis. Folia Biol (Praha) 58: 166-172, 2012.

38. Matsuda Y, Minagawa T, Okui T and Yamazaki K: Resveratrol suppresses the alveolar bone resorption induced by artificial trauma from occlusion in mice. Oral Dis 24: 412-421, 2018

39. Atienzar AN, Camacho-Alonso F and Lopez-Jornet P: Effects of resveratrol and irradiation upon oral squamous cell carcinoma cells. Acta Odontol Scand 72: 481-488, 2014

40. Kim MO, Jung H, Kim SC, Park JK and Seo YK: Electromagnetic fields and nanomagnetic particles increase the osteogenic differentiation of human bone marrow-derived mesenchymal stem cells. Int J Mol Med 35: 153-160, 2015.

41. Erdem A, Metzler D, Cha DK and Huang CP: The short-term toxic effects of $\mathrm{TiO}_{2}$ nanoparticles toward bacteria through viability, cellular respiration, and lipid peroxidation. Environ Sci Pollut Res Int 22: 17917-17924, 2015.

42. Deng Z, Jin J, Wang Z, Wang Y, Gao Q and Zhao J: The metal nanoparticle-induced inflammatory response is regulated by SIRT1 through NF- $\kappa \mathrm{B}$ deacetylation in aseptic loosening. Int J Nanomedicine 12: 3617-3636, 2017.

43. Lee AM, Shandala T, Nguyen L, Muhlhausler BS, Chen KM, Howe PR and Xian CJ: Effects of resveratrol supplementation on bone growth in young rats and microarchitecture and remodeling in ageing rats. Nutrients 6: 5871-5887, 2014.

44. Zainabadi K, Liu CJ and Guarente L: SIRT1 is a positive regulator of the master osteoblast transcription factor, RUNX2. PLoS One 12: e0178520, 2017.

45. Pirapaharan DC, Olesen JB, Andersen TL, Christensen SB, Kjærsgaard-Andersen P, Delaisse JM and Søe K: Catabolic activity of osteoblast lineage cells contributes to osteoclastic bone resorption in vitro. J Cell Sci 132: jcs229351, 2019.

This work is licensed under a Creative Commons Attribution-NonCommercial-NoDerivatives 4.0 International (CC BY-NC-ND 4.0) License. 